\title{
The impact of a structured floral arrangement (SFA) program on caregivers' mental health: A pilot study
}

\author{
Hiroko Mochizuki-Kawai ${ }^{1 *}$, Izumi Kotani ${ }^{2,3}$, Satoshi Mochizuki ${ }^{4}$ and Yuriko Yamakawa ${ }^{5}$ \\ ${ }^{1}$ Institute of Vegetable and Floriculture Science, National Agriculture and Food Research Organization (NARO), Tsukuba, 305-0852, Japan \\ ${ }^{2}$ Graduate School of Humanities and Social Science, University of Tsukuba, Tsukuba 305-8571, Japan \\ ${ }^{3}$ Sase Total Care Center Co., Ltd., Moriya, 302-0110, Japan \\ ${ }^{4}$ Department of Clinical Psychology, Faculty of Social Policy and Administration, Hosei University, Machida 194-0298, Japan \\ ${ }^{5}$ Ibaraki Prefectural University of Health Sciences Hospital, Ami 300-0331, Japan
}

\begin{abstract}
Good mental health of caregivers is crucial for maintaining strong relationships between caregivers and care-recipients, which in turn is important for positive caregiving outcomes. We have developed a structured floral arrangement (SFA) program for neurocognitive disorders to improve visuospatial memory, whereby patients are asked to arrange real flowers and leaves according to an instruction sheet, and then take the arrangements back home to enjoy with their caregivers (family members or care staff). Previous studies with the SFA program revealed that it improves the visuospatial memory of treated patients and the production of the arrangements encouraged them to continue the cognitive training. However, the impact of the arrangements on mental health of the caregivers at home has been unclear. We therefore investigated the effects of these floral arrangements on primary caregivers' mental health. Our results showed that the mean total GHQ-28 score of caregivers improved significantly when spending time with the arrangements $(\mathrm{P}<0.05)$, although no changes were found in control caregivers who were not exposed to arrangements in the home. Mean scores of the GHQ-28 Anxiety and Insomnia sub-category was significantly improved in caregivers exposed to the arrangements. These results suggest that caregivers are affected positively by arrangements of real flowers and leaves made by their care-recipients. The SFA program could therefore contribute to improving the mental health of caregivers as well as the visuospatial memory of patients with neurocognitive disorders.
\end{abstract}

\section{Introduction}

Experiences of psychological, behavioural and physical symptoms associated with neurocognitive disorders are stressful and result in a decline of physical and mental health levels of not only care-recipients but also their caregivers [1-3]. Influences on the mental state of caregivers have been frequently studied and depression has been reported as one of the more common negative effects of caregiving [3]. Declining mental health can become a risk factor for the deterioration of the relationship between a caregiver and the care-recipient. Good mental health and a positive relationship are crucial for positive caregiving outcomes and slow care-recipients' cognitive and functional decline [4]. Dealing with the mental health problems of caregivers is important in nursing care involving neuropsychological disorders.

There are many therapies and interventions for caregivers that care for those with neurocognitive disorders [1,5-8]. However, metaanalyses have shown that multiple therapeutic interventions have difficulty reducing caregivers' mental and physical symptoms [1] and that the benefits of interventions are either modest or inconsistent [7].

Previous studies reported that more positive outcomes occur when interventions target both caregivers and recipients simultaneously rather than either alone [2,5,7-9].

Logiudice and colleagues [10] reported that caregivers exhibit improvements in psychosocial health relevant to quality of life through interventions that include counselling, education and care planning for caregivers as well as cognitive assessment of demented patients. Homebased cognitive stimulation therapy has also been reported to reduce caregiver burden when caregivers and demented recipients are engaged in an exercise and/or game together [9]. Thus, it seems important to intervene with both patients and caregivers simultaneously in order to improve caregivers' mental states.

We have developed a structured floral arrangement (SFA) program as cognitive training (CT) for patients with psychiatric or neurocognitive disorders [11-13]. SFA participants were asked to arrange cut flowers and leaves on absorbent foam according to an instruction sheet as part of a day-care program. The SFA program improved visuospatial processes and spatial memory and encouraged continuous participation in patients with neurocognitive or psychiatric disorders $[11,13]$. The SFA program has benefits similar to horticultural therapy. Treated patients took home the natural arrangements and enjoyed these works with their caregivers (family members or care staffs) $[11,13]$. The arranged flowers and leaves were expected to support coping with stresses not only patients but also their family caregivers or care workers in each home. The SFA program may indirectly affect caregivers through the floral arrangements made by the care-recipients

${ }^{\star}$ Correspondence to: Hiroko Mochizuki-Kawai, $\mathrm{PhD}$, Institute of Vegetable and Floriculture Science, National Agriculture and Food Research Organization (NARO), 2-1 Fujimoto, Tsukuba, Ibaraki 305-0852, Japan, Tel: 81298386821; Fax: 81298386842, E-mail: hirokom@affrc.go.jp

Key words: general health questionnaire (GHQ), floral arrangement, horticultural therapy, motivation, neurocognitive disorder, cognitive training

Received: September 29, 2018; Accepted: October 12, 2018; Published: October 15,2018 
during the intervention; however, no data on the impact of the SFA program on the mental health of caregivers has been collected to date.

The aim of this study was to investigate positive effects on primarily caregivers of keeping floral and leaf arrangements in the home during the SFA intervention. We used a general health questionnaire (GHQ) as a measurement instrument. The GHQ is a brief, consistent and reliable instrument developed by Goldberg and Hillier [14] and is one of the commonly used questionnaires for the detection of mental problems. To clarify that the effects of the SFA program were related to the use of natural materials, we examined the effect of SFA interventions using real flowers and leaves or coloured sticks in patients with neurocognitive disorders and compared the change of GHQ scores between "Flower" group and "Stick" group caregivers. GHQ scores were expected to improve only in Flower group caregivers whose patients worked with real flowers and leaves during the SFA program, and who spent time at home with the resulting arrangements.

\section{Materials and Methods}

\section{Participants}

We performed cognitive interventions using the SFA program in patients with neurocognitive disorders at two day-care facilities. The patients had neuropsychological disorders due to stroke, traumatic brain injury (TBI) and other related disorders. We also recruited their primarily caregivers to participate the study. Fifteen caregivers participated: 11 females and 4 males with a mean age of $52.8(\mathrm{SD} \pm 17.0)$ years. Among the 15 caregivers, 5 were partners, 6 were parents and 4 were unrelated to the patients.

The patients (care-recipients) received 3 sessions of SFA over 8 days (Figure 1) using real flowers and leaves (Figure 2a) or coloured sticks (Figure 2b) at each day-care facility. Nine patients used real flowers and leaves and the remaining 6 used sticks in the SFA sessions. After each SFA session with flowers and leaves, patients took their arrangements home with them, while patients that used sticks went back with nothing. The 9 caregivers ( 7 females and 2 males, mean age 52.6 years, $\mathrm{SD} \pm 15.3$ ) whose patients worked with real flowers and leaves during the SFA program were assigned to the Flower group. The caregivers of the Flower group spent time at home with the real flowers and leaves arranged by their care-recipients. The remained 6 caregivers ( 4 females and 2 males, mean age 53.2 years, $S D \pm 19.2$ ) assigned to the Stick group spent their time in home as usual.

This study was approved by the Ethics Committees of the University of Ibaraki Prefectural and the University of Health Sciences Hospital.

SFA session with flowers and leaves, or coloured sticks

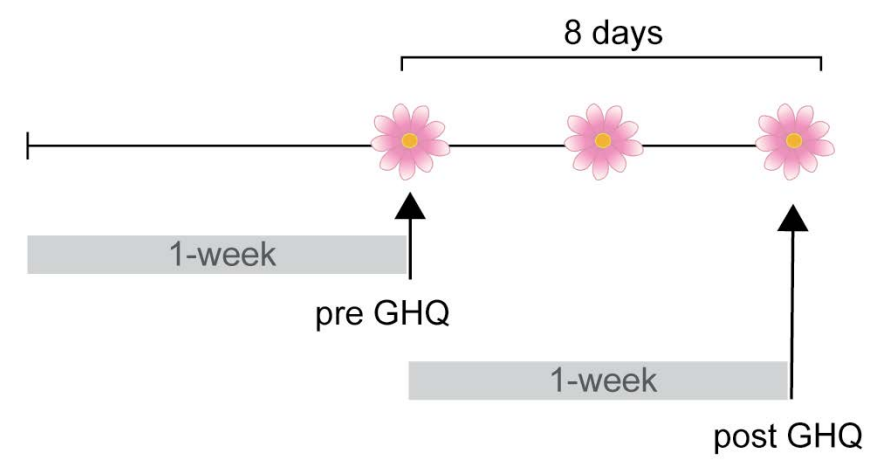

Figure 1. Experimental design (a) flowers and leaves

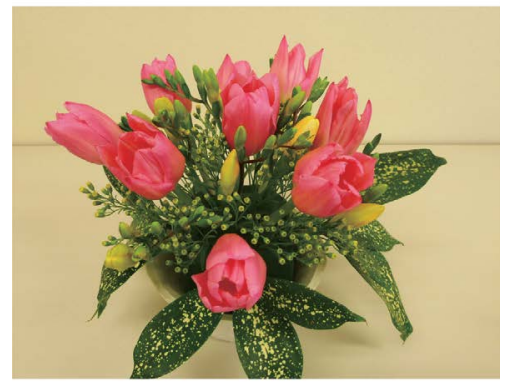

(b) coloured sticks

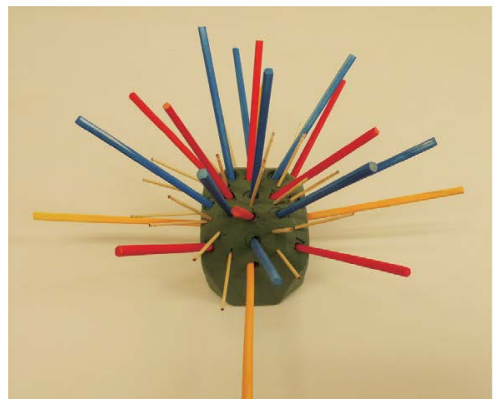

Figure 2. Examples of arrangements producing in the SFA program, including one made with real flowers and leaves (a) and with coloured sticks (b)

We obtained written informed consent from all adult participants who were over 24 years old before their participation in the study.

\section{Procedure}

A Japanese version of the 28-item general health questionnaire (GHQ-28) was used to probe individuals' psychological states. Caregivers were asked to answer the GHQ-28 on the first and last days of SFA intervention (Figure 1). Caregivers answered with respect to status over the preceding week (Figure 1). To detect changes in mental health state affected by the real flowers and leaves, we compared preand post-GHQ-28 scores in the Flower group. We employed a '0-0-11 ' scoring method, in which 0 was scored for the two lesser responses ('better than usual' or 'same as usual') and 1 was scored for the two greater responses ('less than usual' or 'much less than usual') $[15,16]$. The scores were summed by adding all items to produce a rating range from 0 to 28, and a 5/4 cut-off point was used, where individuals with a score of 5 or above were classified as having poor mental health. The GHQ-28 scores were also divided into 4 sub-scales: Somatic Symptoms, Anxiety and Insomnia, Social Dysfunction, and Severe Depression. We analysed the total and sub-scores by using a Wilcoxon signed rank or Mann-Whitney U tests.

\section{Results}

We received self-reported questionnaires from all 15 caregivers. Figure 3 shows the mean total GHQ-28 scores. The Flower group care-recipients' mean total scores decreased significantly over the intervention period and was below the cut-off threshold (5) in the post-test $(\mathrm{P}<0.05)$. The number of caregivers that were recognized as having poor mental health (i.e. scored over 5 points in the GHQ-28) decreased from 5 to 3 in the Flower group. In contrast, the mean total scores of Stick group did not exhibit a decrease and remained above 5 both before and after treatment (Figure 3 ). The number caregivers with poor mental health remained unchanged ( 3 persons) in Stick group. 
Changes in GHQ-28 sub-scores are shown in Figure 4. Mean scores were significantly decreased in the of Anxiety and Insomnia category only in the Flower group (Figure $4 \mathrm{~b}, \mathrm{P}<0.05$ ). There was also a tendency toward improvement between pre- and post-scores in the Social Dysfunction category in the Flower group, although this was not significant (Figure $4 \mathrm{c}, \mathrm{P}<0.10$ ). No significant changes were observed in the other categories.

\section{Discussion}

Our results revealed that mean total GHQ-28 scores decreased significantly only in caregivers who spent time with the natural arrangements made by their care-recipients. The positive effects especially evident in two sub-categories of the GHQ-28: Anxiety

\section{GHQ total score}

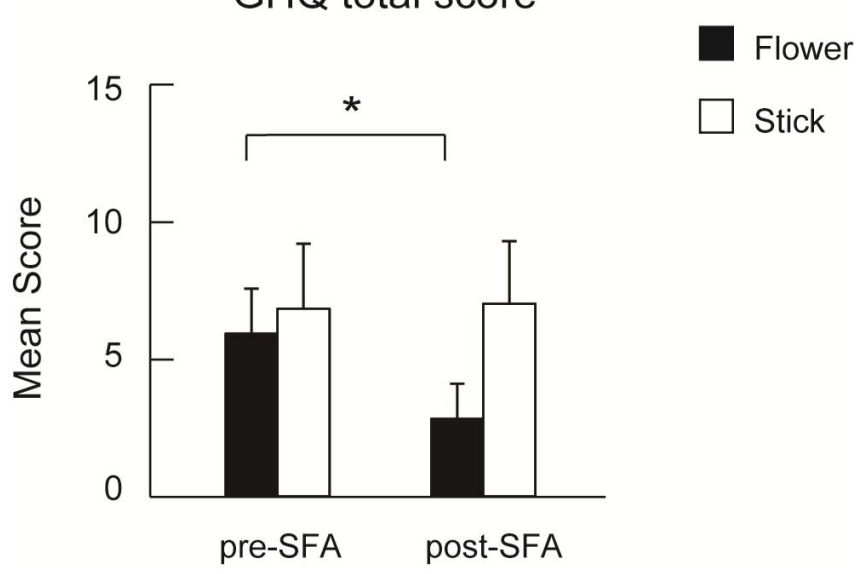

Figure 3. Mean GHQ-28 total scores pre- and post-intervention (" $\mathrm{p}<0.05)$

\section{- Flower $\square$ Stick}

(a) Physical Symptoms

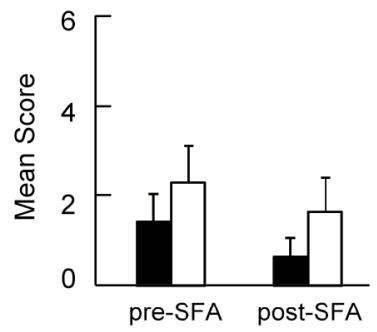

(c) Social Dysfunction

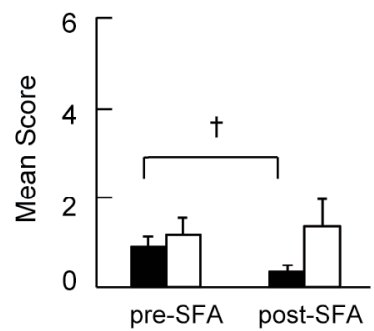

(b) Anxiety and Insomnia

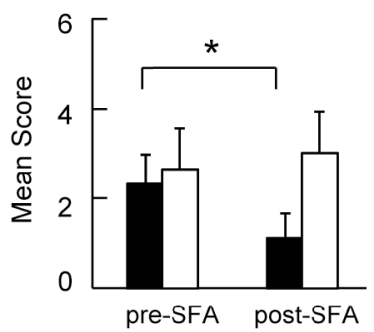

(d) Severe Depression

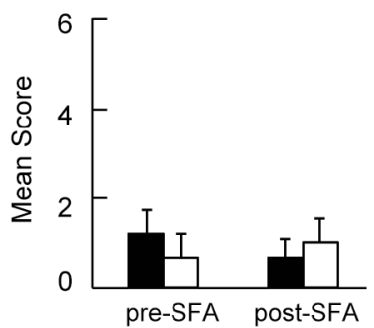

Figure 4. Mean GHQ-28 sub-scores pre-and post-interventions $\left({ }^{\dagger} \mathrm{p}<0.10 ;{ }^{*} \mathrm{p}<0.05\right)$ and Insomnia and Social Dysfunction. The present results suggest that the SFA program using real flowers and leaves contributes to the improvement of caregivers' quality of sleep and/or the enhancement of their self-evaluation of daily activities, thereby improving their mental health level at home.

SFA intervention reduced total mean GHQ-28 scores to below the cut-off threshold (5 points) only in caregivers in the Flower group and not in the Stick group. Thus, the use of real flowers and leaves during SFA is essential for positively affecting caregivers' mental health, though training with sticks was sufficient as CT for patients with neurocognitive disorders [13]. Caregivers were therefore supported emotionally when their care-recipients participated in the SFA program using flowers and leaves. Although the SFA program directly treats patients, it can indirectly affect their caregivers through the arrangements produced by the patients. It is a unique feature of the SFA program that treated patients can positively affect their caregivers through their participation.

Cognitive outcomes were the focus of previous studies of the SFA program [11] and psychological benefits were not assessed in detail in treated patients [13]. This is the first study to reveal the psychological benefits in caregivers of the SFA program using real flowers and leaves. Similar results have been reported where cognitive intervention involving both demented patients and caregivers produces positive outcomes to caregivers rather than the mental state of the treated patients [9].

Arrangements with flowers and leaves might affect caregivers emotionally, and natural materials may help to support stress-coping mechanisms relevant to nursing care [17-19]. The coping strategy with flowers and leaves is classified as one of emotionally focused ones. Although emotion-focused strategies such as wishful thinking, denial and avoidance have reported poorer outcomes in mental health than problem-focused ones for caregivers [6], our study revealed benefits. The natural arrangements were produced by care-recipients, which might explain the present positive outcomes. Care-recipients seemed to take back the natural arrangements as gifts for their family members or care staffs during the SFA program. The natural gifts might efficiently induce conversations among family members or care staffs and support stress coping for caregivers. Our results agree with previous studies that psychological interventions involving both patients and caregivers are more effective than those involving just caregivers [1,5]. The SFA program using real flowers and leaves can affect both caregivers' mental health and patients' cognition simultaneously [13] without taking caregivers' time for attending interventions together.

\section{References}

1. Acton GJ, Kang J (2001) Interventions to reduce the burden of caregiving for an adult with dementia: a meta-analysis. Res Nurs Health 24: 349-360. [Crossref]

2. Aguirre E, Hoare Z, Spector A, Woods RT, Orrell M (2014) The effects of a Cognitive Stimulation Therapy [CST] programme for people with dementia on family caregivers' health. BMC Geriatr 14: 31. [Crossref]

3. Schulz R, Sherwood PR (2008) Physical and mental health effects of family caregiving. Am J Nurs 108: 23-27. [Crossref]

4. Quinn C, Clare L, McGuinness T, Woods RT (2012) The impact of relationships, motivations, and meanings on dementia caregiving outcomes. Int Psychogeriatr 24: 1816-1826. [Crossref]

5. Brodaty H, Green A, Koschera A (2003) Meta-analysis of psychosocial interventions for caregivers of people with dementia. J Am Geriatr Soc 51: 657-664. [Crossref]

6. Gilhooly KJ, Gilhooly ML, Sullivan MP, McIntyre A, Wilson L, et al. (2016) A metareview of stress, coping and interventions in dementia and dementia caregiving. $B M C$ Geriatr 16: 106. [Crossref] 
7. Smits CH, de Lange J, Dröes RM, Meiland F, Vernooij-Dassen M, et al. (2007) Effects of combined intervention programmes for people with dementia living at home and their caregivers: a systematic review. Int J Geriatr Psychiatry 22: 1181-1193. [Crossref]

8. Sörensen S, Pinquart M, Duberstein P (2002) How effective are interventions with caregivers? An updated meta-analysis. Gerontologist 42: 356-372. [Crossref]

9. Orrell M, Yates L, Leung P, Kang S, Hoare Z, et al. (2017) The impact of individual Cognitive Stimulation Therapy (iCST) on cognition, quality of life, caregiver health, and family relationships in dementia: A randomised controlled trial. PloS Med 14: e1002269. [Crossref]

10. Logiudice D, Waltrowicz W, Brown K, Burrows C, Ames D (1999) Do memory clinics improve the quality of life of carers? A randomized pilot trial. Int J Geriat Psychiatry 14: 626-632. [Crossref]

11. Mochizuki-Kawai H, Yamakawa Y, Mochizuki S, Anzai S, Arai M (2010) Structured floral arrangement program for improving the visuospatial working memory in schizophrenia. Neuropsychol Rehabil 20: 624-636.

12. Mochizuki-Kawai H (2016) Structured floral arrangement program developed for cognitive rehabilitation and mental health care. JARQ 50: 39-44.
13. Mochizuki-Kawai H, Kotani I, Mochizuki S, Yamakawa Y (2018) Structured floral arrangement program benefits in patients with neurocognitive disorder. Front Psychol 9: 1328 .

14. Goldberg DP, Hillier VF (1979) A scaled version of the general health questionnaire. Psychol Med 9: 139-145. [Crossref]

15. Goldberg D, Williams PA (1988) User's guide to the general health questionnaire. Windsor: NFER-Nelson.

16. Leignel S, Schuster JP, Hoertel N, Poulain X, Limosin F (2014) Mental health and substance use among self-employed lawyers and pharmacists. Occup Med (Lond) 64: 166-171. [Crossref]

17. Lee MS, Park BJ, Lee J, Park KT, Ku JH, et al. (2013) Physiological relaxation induced by horticultural activity: transplanting work using flowering plants. J Physiol Anthropol 32: 15. [Crossref]

18. Hartig T, Evans GW, Jamner LD, Davis DS, Gärling T (2003) Tracking restoration in natural and urban field settings. J Environ Psychol 23: 109-123.

19. Park SH, Mattoson RH (2009) Therapeutic influences of plants in hospital rooms on surgical recovery. HortScience 44: 102-105.

Copyright: $(2018$ Mochizuki-Kawai H. This is an open-access article distributed under the terms of the Creative Commons Attribution License, which permits unrestricted use, distribution, and reproduction in any medium, provided the original author and source are credited. 